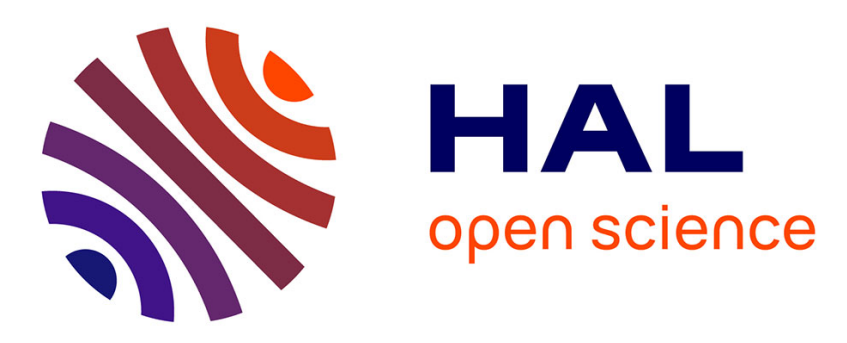

\title{
An application of a cocitation-analysis method to find further research possibilities on the area of scheduling problems
}

Tibor Kocsis, Stéphane Négny, Pascal Floquet, Xuan Mi Meyer, Endre Rev

\section{- To cite this version:}

Tibor Kocsis, Stéphane Négny, Pascal Floquet, Xuan Mi Meyer, Endre Rev. An application of a cocitation-analysis method to find further research possibilities on the area of scheduling problems. European Symposium on Computer Aided Process Engineering - ESCAPE 20, Jun 2010, Ischia, Italy. pp. 1165-1170. hal-00880649

\section{HAL Id: hal-00880649 https://hal.science/hal-00880649}

Submitted on 6 Nov 2013

HAL is a multi-disciplinary open access archive for the deposit and dissemination of scientific research documents, whether they are published or not. The documents may come from teaching and research institutions in France or abroad, or from public or private research centers.
L'archive ouverte pluridisciplinaire HAL, est destinée au dépôt et à la diffusion de documents scientifiques de niveau recherche, publiés ou non, émanant des établissements d'enseignement et de recherche français ou étrangers, des laboratoires publics ou privés. 


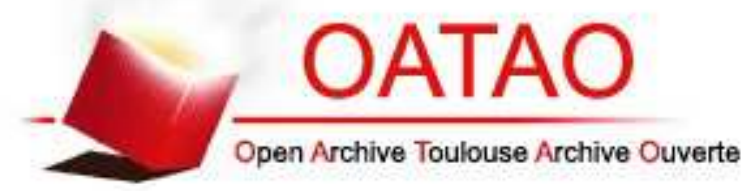

\section{Open Archive TOULOUSE Archive Ouverte (OATAO)}

OATAO is an open access repository that collects the work of Toulouse researchers and makes it freely available over the web where possible.

This is an author-deposited version published in : http://oatao.univ-toulouse.fr/ Eprints ID : 10014

To cite this version : Kocsis, Tibor and Negny, Stéphane and Floquet, Pascal and Meyer, Xuan $\mathrm{Mi}$ and Rev, Endre. An application of a cocitation-analysis method to find further research possibilities on the area of scheduling problems. (2010) In: European Symposium on Computer Aided Process Engineering - ESCAPE 20, 06 June 2010 - 09 June 2010 (Ischia, Italy).

Any correspondance concerning this service should be sent to the repository administrator: staff-oatao@ listes-diff.inp-toulouse.fr 


\title{
An Application of a Cocitation-Analysis Method to Find Further Research Possibilities on the Area of Scheduling Problems
}

\author{
T. Kocsis ${ }^{\mathrm{a}-\mathrm{b}}$, S. Negny ${ }^{\mathrm{a}}$, P. Floquet ${ }^{\mathrm{a}}$, X. Meyer ${ }^{\mathrm{a}}$, E. Rév $^{\mathrm{b}}$ \\ ${ }^{a}$ Université de Toulouse LGC UMR 5503 - INPT ENSIACET, 4 allée Emile Monso BP \\ 74 2333, 31432 Toulouse Cedex 4, FRANCE \\ ${ }^{b}$ Budapest University of Technics and Economics, Department of Chemical and \\ Environmental Process Engineering, Budafoki út 8, 1111 Budapest, HUNGARY, \\ kocsis.tibor@gmail.com
}

\begin{abstract}
In this article we will give firstly a classification scheme of scheduling problems and their solving methods. The main aspects under examination are the following: machine and secondary resources, constraints, objective functions, uncertainty, mathematical models and adapted solution methods.

In a second part, based on this scheme, we will examine a corpus of 60 main articles (1015 citation links were recorded in total) in scheduling literature from 1977 to 2009. The main purpose is to discover the underlying themes within the literature and to examine how they have evolved. To identify documents likely to be closely related, we are going to use the cocitation-based method of Greene et al. (2008).

Our aim is to build a base of articles in order to extract the much developed research themes and find the less examined ones as well, and then try to discuss the reasons of the poorly investigation of some areas.
\end{abstract}

Keywords: Scheduling, Classification, Cocitation Analysis, Review

\section{Introduction}

Scheduling is a critical issue in process operations for improving production performance. In the last twenty years, there have been significant research efforts regarding this area, and several excellent reviews have been published. Esquirol Lopez (1999) showed the areas of scheduling with a detailed review on them, Mendez (2006) and Pinedo (2008) delivered articles classifying scheduling problems and their solution methods.

A brief description of the problem is the following (Taillard (1989)): $\mathrm{n}$ jobs have to be performed on $\mathrm{m}$ unrelated machines; usually every job consists of $\mathrm{m}$ non-preempting operations. Every operation of a job uses a different machine during a given time, and usually (but not always) may wait before being processed.

The aim of this paper is to deliver a classification of these problems, and to find out which areas are well examined, and which ones less. To find the interesting areas we are going to use the method described by Greene et al. (2008), who used a special technique based on cocitation-analysis to give a classification and show the connecting areas of their research area, Case-Based Reasoning (CBR) problems. 


\section{Classification of scheduling problems and their solution methods}

We classify the problems under the following main aspects: machines and secondary resources, constraints, objectives, uncertainty, mathematical models and adapted solution methods.

The first aspect is the number and connection scheme of machines. We can speak about one machine, parallel machines and more machines. A job is a set of operations visiting different machines and sequenced in a linear manner along a chain. By the way followed by jobs there are 3 main categories: FlowShop Scheduling Problems (FSSP), JobShop Scheduling Problems (JSSP) and OpenShop Scheduling Problems (OSSP). Certainly, flow shop problem is the most examined one. We can find details, and also methods in Taillard (1989) to generate, examine and solve problems.

Sometimes tasks require multiple resources, such as a machine operator. These resources can be renewable (disjunctive or cumulative), or consumable. An example is employee timetabling.

We can distinguish constraints of functionality, techniques, societals, economics, lifecycle. Among them most frequently we meet functionality constraints, defining special cases, which are in some way different from the typical one, i.e. they do not use, partially or at all, the assumptions applied in general. For example: preemption, stocking (capacity or waiting time), process-time dependence on size, transit time, overlap, due-dates, cleaning/maintenance, availability of resources, etc.

Objective functions can be time-based, resource-based, cost-based, income-based, environmentals and even multi-objectives.

Many research studies focus on optimizing the makespan under static conditions and do not take into consideration dynamic disturbances such as machine breakdown or new job arrivals. Regarding to this aspect we can distinguish static and dynamic shop scheduling problems. There are many attempts to describe stochastic problems also, i.e. when we work with attended values and variances instead of fixed starting times and durations.

The mathematical model of a problem contains an objective function (to be minimized or maximized), and several constraints. Regarding to linearity there are linear and nonlinear models, regarding to variables we can speak about integer, continuous, or mixed integer problems. By difficulty it can be polynomial (i.e. in function of the number of variables there are an algorithm that can find the solution in a polynomial time) or NP (i.e. the time needed is depending on the size of the problem exponentially). Mainly in the process scheduling models we can distinguish also the time representation (discrete-continuous) models, material balance (network flow or lots), and eventrepresentation (time intervals, time events, time slots) models.

The most important solution methods are the following ones: exact methods, artificial intelligence methods, heuristics, metaheuristics and decomposition strategies.

Exact methods use the technique of mathematical programming, especially the mixedinteger linear programming methods (most scheduling problem can be formulated as an MILP problem). AI methods are constraint-satisfaction programming (CSP), case-based reasoning applications, neural network, multiagent-systems, expert systems, logic flow, etc. For more details see Gabot (2009). Heuristic methods can be constructive, which from zero construct a new solution, and ameliorative creating a solution as a skeleton, and step by step try to ameliorate it. We mention here the well-known NEH heuristic (from the names of the authors: Nawaz, Encore and Ham).

. Most heuristics are due-date or process-time based ones. Metaheuristic methods in general need some existing solutions to ameliorate. So, they can used to complete heuristic methods. They are inspired by some analogy for example from physics 
(simulated annealing, simulated diffusion), biology (genetic algorithms, taboo search), or ethology (ant colony optimization). A good review in this area is the book of Xhafa and Abraham (2008). Finally, there are decomposition strategies regarding to time, machines and tasks or resources. A famous example of decomposition by time is the socalled Rolling Horizon technique.

\section{Cocitation analysis}

To identify documents likely to be closely related, two techniques have been devised: bibliographic coupling and cocitation analysis (Smith (1981)). Two documents are bibliographically coupled if their reference lists share one or more of the same cited papers, and two documents are cocited when they are jointly cited in one or more subsequently published documents.

In their work Greene et al (2008) set out to examine the themes that have evolved in their domain research as revealed by the implicit and explicit relationships between the conference papers, after 15 years of conferences. They have found that a clustering based on co-citation of papers appears to produce the most meaningful organization. Their idea inspired us to apply a similar method to the area of scheduling.

The concept of cocitation analysis is illustrated in Fig. 1. Let for example P1 and P2 be two related articles. The fact that P3 and P4 are cited both by P1 and P2 indicates a strong relationship between these papers. In this example cocitation analysis suggests a weaker relationship between P3 and P5 and P4 and P5 based on cocitation in P2.

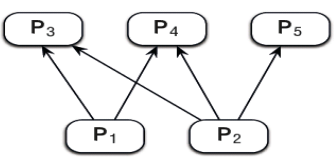

Fig. 1. The concept of cocitation

Rather than using raw co-citation indices as a basis for measuring the similarity between papers, they use a so-called CoCit-Score which has been shown to be a particularly effective choice for clustering co-citation data. The similarity between a pair of papers $(\mathrm{Pi}, \mathrm{Pj})$ is given by normalizing their co-citation frequency with respect to the minimum and mean of the pair's respective citation counts:

$S_{i j}=\frac{C_{i j}{ }^{2}}{\min \left(C_{i i}, C_{j j}\right) \times \operatorname{mean}\left(C_{i i}, C_{j j}\right)}$

To illustrate this equation, suppose that Paper A is cited 26 times, Paper B 18 times, and they are cited together 7 times. In this case $S_{i j}=\frac{7^{2}}{\min (18,26) \times \text { mean }(18,26)}=0.124$

Each entry is now in the range [0,1], where a larger value indicates a stronger association between the papers. When we know these association values, we can arbitrarily choose a value (for example 0.05) which we treat as an association ,strong enough". Using these values we classify the articles into groups, and regarding these groups we can distinguish the larger research areas existing in the literature. Regarding to the timeline it is possible by this way to show the intensity of research, i.e. the importance of an article in the research area. It can also be seen whether an area is under research, because in this case we see the dynamism on the diagram, or it is well researched, when we see a large intensity during a couple of year, and fewer and fewer articles later. 
If we represent papers by bubbles on the diagram, the size of a bubble can respect to the total number of citation of an article, and by that we can deduct to the relevance of the adequat paper.

In the next chapter, we will show an example of application of this method, in our case to the scheduling literature.

\section{Application of the method to scheduling literature}

To examine the connections among articles in the literature of scheduling problems, we used Elsevier Science Direct $\odot$, to find works in this area. Arbitrarily we have chosen 60 articles, and followed the 1015 cocitation links in the search motor of Science Direct. Several articles have not yet been cited because they are new ones. The results for each article have been saved by Reference Manager@ $@$. The databases have been exported to Microsoft Excel, and sorted in order to find out cocitations, and to calculate the CoCitScore values. The sum of these values for an article we call global centrality. There is a local degree centrality too, based on co-citation counts from the CoCit Score values. Firstly, for each cluster we assign the papers if their previous membership weight for that cluster exceeds a given threshold (we used 0.1 as Greene et al (2008) proposed). This yields to scores in the range $[0,1]$, where a higher score indicates that a paper is more influential in the area of research.

\subsection{Analysis}

First we will make our remarks on the articles of scheduling literature in general, and later we will show the results for the two special areas. On Fig. 2. gray bubble means a production scheduling article, and white a process scheduling one. We can see centrality values of the examined articles on the timeline (the size of a bubble shows the total citation number of the corresponding article).

Scheduling literature is far from being a finished, well-researched area yet, there is significant activity in last years also. After some very important basic article from the early nineties, the area is in dynamic evolution, and this trend seems to be continued.

Now, if we regard the cocitations, among the articles we can find two significant groups of papers. The first one belongs to process scheduling, and the second one to production scheduling. For each area there is actually significant research activity, and these two groups are being examined in a parallel way.

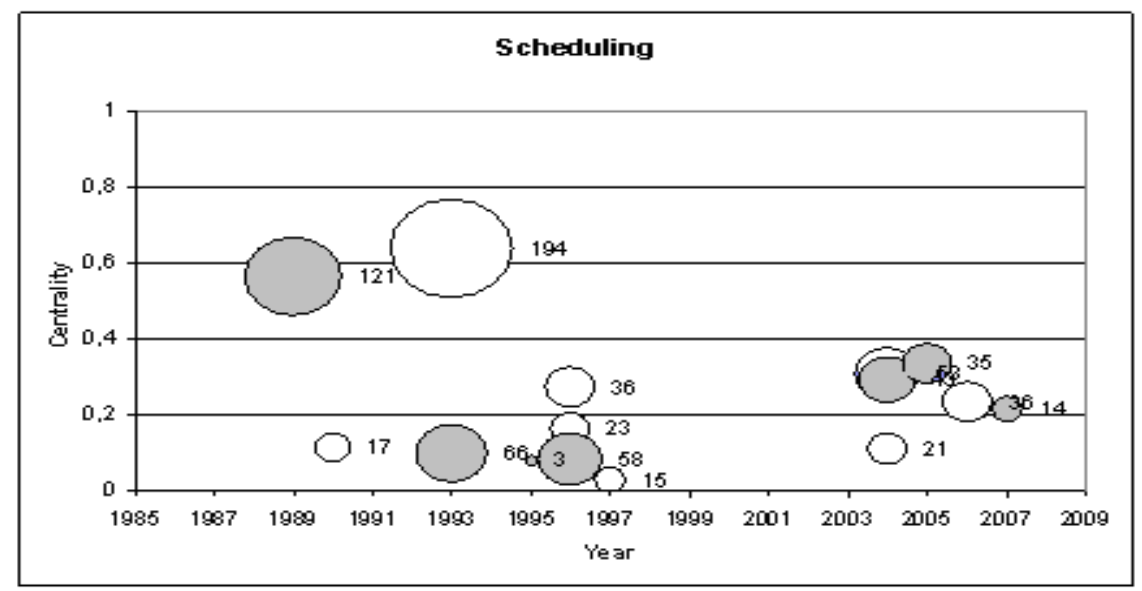

Fig.2. Some relevant paper in scheduling literature 


\subsection{Comments on results and referring to classification}

In this part we will make the connection between our classification scheme, and the founded two domains in the literature. We are going to try to discuss why certain types are typical to both of these domains, to one and not the other, or to neither of them.

\subsubsection{Machines}

Regarding to the number of machines both area focuses mostly to more machine problems. Of course there are several theoretical studies for the special cases of one or parallel machines, but in real life most often we meet with more machine problems.

In the production scheduling (PDS) area, the permutation flowshop problems are clearly dominating the others. Non-permutation flow shop and job shop problems are also well treated, but there are only a few articles on open shop problems. Closed circle is rarely appears in the network. Poorly are examined yet the hybrid shops (flexibility).

On the other hand, in the process engineering, process scheduling (PSS) area multiproduct and multipurpose batch plant scheduling problems are the most examined ones; literature calls them flow shop and job shop problems also (but these expressions in this context means not exactly the same as generally). Several excellent reviews can be found, for example Mendez et al. (2006). Flexibility is widespread, machines are usually independents.

\subsubsection{Secondary resources}

In PDS, secondary resources are rarely treated; an exception is integrated scheduling and employee timetabling problems. However, in PSS we can find more examples, especially energy-requirements of machines, raw materials or other resources.

\subsubsection{Constraints}

Regarding functionality constraints an unexamined aspect is the limited wait time, for both areas. We can find several examples for unlimited and zero wait problems, but only few for the limited ones. Nevertheless, stocking and waiting-time constraints are more often in PSS, because of the problem structure, and the evident need of material treating requirements. There is no differentiation made between finite intermediate storage and limited waiting time, maybe for practical reasons.

Process times are usually invariable for PDS but often depend on size or resource linearly (or sometimes even exponentially) in PSS. Exponential dependence is much less often, because of the need of an MINLP model in this case, which would be much more difficult than an MILP one.

Overlapping and connections between jobs are also rare especially for PDS area (only few exception, maybe because it is a really hard problem), maintenance or cleaning are rarely taken into account, and we've found no example for the time-dependent maintenance. Process dependent maintenance occurs almost only in PSS. Overlapping or availability information can be included in the superstructure representation of a PSS much easier, on the other hand transit time is easier to deal with in PDS.

Another unexamined area is the one of non-functional constraints, practically no example (in our base) for technical, societal or lifecycle constraints in neither area. However, there are some exceptions on the taking into account environmental considerations for PSS.

\subsubsection{Objective functions}

In PDS problems the objective function most often is the makespan, or some other function of time-based type in PDS area, and there is practically no example for resource, revenue, environmental or cost-based criteria. In PSS cost or revenue-based objective functions are typical, most frequently the total profit. 


\subsubsection{Uncertainty}

Dynamic disturbances such as machine breakdown or new job arrival are taken into account sometimes in PDS problems, but not widespread in PSS. However it is not too difficult to deal with, for example by modifying the superstructure and use a Rolling Horizon technique.

Stochastic approaches on the other hand we found for some PSS problems.

\subsubsection{Mathematical models and adapted solution methods}

For both areas mathematical models are mixed integer linear ones. As we mentioned before, in PSS the exponential dependence causes an MINLP model. In PDS precedence-based ones dominate, most frequently articles treat $\mathrm{N} \sim \mathrm{M}$ problems. On the other hand, in PSS problems event representation is an important characteristic of the model, time-interval based models are the oldest ones, global and unit-specific time point based models are newer. First ones are sometimes (if we have not enough intervals) not enough accurate, but later ones usually need more computational time.

Material balances are important in PSS, but not so in PDS, as here we have to deal usually only with the continuity of a job, and not with quantities. In PDS we also don't need time-representation equations. Despite of that, because of the objective function, PDS problems are usually hard to deal with exact methods. Most often we find heuristic and metaheuristic solution methods for them.

On the other hand, for the PSS problems we can meet more often exact methods. Heuristics are appearing only for larger problems. A specific method family is the decomposition strategy, which is missing in production scheduling. The most famous one is the so-called Rolling Horizon.

For both great area can be said, that Artificial Intelligency methods are not widespread yet. Except for the CSP the application of AI methods, especially CBR or neuron network techniques deserve further research without doubt.

\section{Conclusion}

We discussed the possibilities and classification of scheduling problems and their solution methods, and regarded several articles. To find poorly examined areas we used the cocitation-based method of Greene et al. (2008). By constructing a base of articles we have shown the much and the less examined areas.

We could see that still exist problem types to be focused on. The application of AI methods and the effects of technical, societal and environmental constraints are to be researched. Some special possibilities have been proposed to further examination. We see continuous research which is far from end, so deserves further work.

\section{References}

Esquirol - Lopez: L'ordonnancement. Paris, Ed ECONOMICA, 1999

Bernard Grabot: Ordonnancement d'ateliers manufacturiers. http://www.techniquesingenieur.fr/book/ag3015/ordonnancement-d-ateliers-manufacturiers.html (2009)

Greene, Freyne, Smyth, Cunningham: An analysis of research themes in the CBR conference literature In: K-D Althoff et al: ECCBR 2008, LNAI 5239 pp 18-43, 2008 Berlin, Springer

Mendez Carlos A. ; Cerda Jaime ; Grossmann Ignacio E. ; Harjunkoski Iiro ; Fahl Marco: Stateof-the-art review of optimization methods for short-term scheduling of batch processes Computers \& Chemical Engineering 30 (2006) 913-946

Pinedo: Scheduling: Theory, algorithms and systems. Prentice Hall, 2008

Smith: Cocitation analysis. In: W.G. Potter: Bibliometrics 83-106 Illinois, 1981

Taillard: Benchmarks for basic scheduling problems ORWP89/21 Dec 1989

Xhafa - Abraham: Metaheuristics for scheduling in industrial and manufacturing applications. Springer, 2008 